\title{
Aproximación teórica sobre la aplicación de la autoría mediata por dominio de organización en supuestos de gran corrupción ${ }^{(*)}$
}

\section{A Theoretical Approach to the Application of Command Responsibility for Domain over Organized Power Structures to High Corruption Cases}

\author{
Erick Guimaray $\left.{ }^{(\star}\right)$ \\ Pontificia Universidad Católica del Perú
}

\begin{abstract}
Resumen: La criminalidad organizada puede partir del propio Estado, de sus cauces jerárquicos y normativos, asegurando la máxima idoneidad lesiva de los delitos que se ejecuten en su seno. La categoría criminológica de gran o alta corrupción describe la sinergia entre el poder político y económico, y con ello, escora el razonamiento hacia la importancia del factor denominado organización estructural. En esta tesitura, y tomando en cuenta los actuales casos de corrupción política que alcanzan a los todos los Presidentes del Perú a partir del año 2000, el uso de criterios de imputación de responsabilidad penal vastamente trabajados desde la doctrina, pero pocas veces utilizados por nuestros operadores de justicia, podría ser una opción viable que coadyuve en el procesamiento judicial de quienes se ubican en el ápice de la Administración. En específico, la aplicación de la tesis de autoría mediata por dominio de aparato organizado de poder sobre supuestos de gran o alta corrupción.
\end{abstract}

Palabras clave: Derecho Penal - Corrupción - Autoría mediata - Criminalidad organizada - Corrupción política - Delincuencia económica

\begin{abstract}
Organized crime can start within the State itself, even from its hierarchical and normative channels, in order to assure the effectiveness of their crimes. High corruption as a criminological category describes the synergy between political and economic power; thus, it obligates us to analyze the importance of the structural organization factor. Taking into account the current cases of political corruption that involve all Peruvian Presidents from the year 2000 onwards, we argue that the use of imputation criteria vastly used in doctrine, but no so much by our justice operators, could be a viable option that helps in the judgment of high officials at the apex of the Administration. Specifically, the application of the thesis of command responsibility for domain over organized power structures to high corruption cases.
\end{abstract}

Keywords: Criminal Law - Corruption - Command responsibility - Organized crime Political corruption - Economic crime

$\left(^{*}\right) \quad$ Nota del Editor: el artículo fue recibido el 14 de marzo de 2019 y su publicación fue aprobada el 4 de mayo de 2019.

${ }^{* *}$ Investigador pre doctoral de la Universidad de Cádiz. Profesor del Departamento de Derecho y de la Escuela de Posgrado de la Pontificia Universidad Católica del Perú. Miembro del Grupo de Investigación y Estudio de Derecho Penal y Criminología de la Pontificia Universidad Católica del Perú. Contacto: evguimaraym@pucp.pe. 


\section{Introducción}

Las principales investigaciones a cargo del Ministerio Público peruano, en cuanto a corrupción se refiere, se centran en empresas consorciadas para delinquir, contratos públicos millonarios y amañados desde las más altas esferas del Estado, campañas presidenciales financiadas como contraprestación de transacciones ilícitas, lavado de dinero en el seno de un partido político, entre otros ítems, y ellas, además de ser cuestiones complicadas que demandan la máxima capacidad técnica e independencia de las Instituciones y sus roles ${ }^{(1)}$, demuestran que hoy en día la corrupción política es expresión del crimen organizado (Terradillos Basoco 2001, 22; De la Mata 2016, 5). Es decir, existe una relación simbiótica entre dichas formas de criminalidad. Por un lado, la corrupción estabiliza el crimen organizado, lo hace rentable y sostenible ${ }^{(2)}$. Y de otro lado, las formas más sofisticadas de corrupción se identifican por el uso de estructuras organizadas, que sincronizan milimétricamente sus componentes en la ejecución del plan criminal, asegurándose suficientes barreras de impunidad, así como un fulgurante enriquecimiento.

Una de aquellas estructuras instrumentalizadas para el crimen de corrupción puede ser la propia distribución burocrática de la Administración, que por sus especiales características constituye un problema particularmente grave. Señaladamente, se trata de la comisión de un delito desde las propias entrañas de una Institución que, por mandato constitucional, debería funcionar únicamente al servicio de la Nación y de sus intereses. Por ende, cuando se le desnaturaliza se hace lo propio con el orden social, con la igualdad y el fin prestacional del Estado. Y además, el armazón administrativo estatal, al aislar o clasificar competencias y responsables, puede generar impunidad, principalmente, respecto del superior jerárquico que dirigió y avaló el crimen (y a esto habrá que sumarle su poder de influencia para evadir la justicia [Kupatadze 2015, 206]). Así las cosas, el aparato público es un factor de riesgo criminógeno, de oportunidad, y esta realidad obliga al Derecho Penal a adecuar su respuesta de la manera más propicia que le sea posible ${ }^{(3)}$.

En este texto se asume el concepto de gran corrupción, esto es, una descripción criminológica que escinde una concreta tipología de corrupción, en virtud de una serie de características de composición y de idoneidad lesiva. La clasificación mencionada implica hacer referencia a ciertas características del crimen organizado, pero no respecto de sus formas de tipicidad más conocidas, como lo son la asociación ilícita para delinquir o la organización criminal, sino a las condiciones o argumentos que sustentan el adjetivo organizado, y que se registran, prima facie, en la gran corrupción.

Luego, con los insumos explicados de forma medianamente razonable, se ensayará la siguiente hipótesis: la tesis de la autoría mediata por dominio de organización es una forma válida de imputación de responsabilidad penal contra los superiores jerárquicos que utilizan el aparato burocrático estatal para cometer delitos de gran corrupción. Y la premisa principal de este texto parte de la distinción entre un injusto de organización, que no es otra cosa que un delito autónomo, y la autoría mediata por dominio de organización, que no es un delito, sino un título y un criterio de imputación.

\section{Sobre la relación criminológica entre la gran corrupción y la criminalidad organizada}

La corrupción es parte negativa de la evolución social de la humanidad, nace con la organización de lo público y es una constante en todo tipo de sociedad (Amisano 2011, 3). Su etiología puede ser enfocada desde distintos planos de análisis, y todos ellos podrán lograr explicar alguna arista de su composición. Sin embargo, en lo que respecta al Derecho Penal, este no puede ocuparse de todas sus causas, y de las que sí, tendrá que hacerlo desde sus propios

(1) Como bien lo reconoce el actual Plan Nacional de Integridad y Lucha contra la Corrupción 2018-2021, Decreto Supremo 044-2018PCM, de fecha 26 de abril de 2018.

(2) Con un sistema corrupto, las posibilidades de éxito y mantenimiento de la actividad criminal son altas, con un ejemplo sobre el tráfico ilegal de fauna en Asia, véase Wyatt y otros (2018, 37-38). Y con referencia al narcotráfico, véase Raffo y Gómez (2017, 237, 247).

(3) “(...) La dogmática jurídico-penal sólo tiene sentido si se puede aportar soluciones adecuadas a las condiciones sociales existentes (...)”, Feijoo Sánchez $(2007,125)$; Meini $(2008 b, 7)$. “(...) La aparición del dominio de la organización responde al hecho que las demás categorías penales, en concreto las reglas de la autoría y participación, son insatisfactorias para explicar y resolver los casos de intervención de los que dirigen y controlan una organización (...)" Sala Penal Nacional, Expediente Acumulado No. 5602003, de fecha 3 de octubre de 2006, 161. "(...) las categorías actuales de autoría y participación no son aptas para determinar la responsabilidad criminal en las estructuras jerárquicamente organizadas (...)", Marín De Espinosa Ceballos $(2002,55)$. 
linderos de razonamiento; es decir, con atención a sus límites y posibilidades.

Es verdad que para hablar de corrupción basta la referencia al aprovechamiento o abuso del poder público en beneficio privado (Ferrajoli, 1996, 18; Aedo 1996, 21; Virgolini 2004, 258; Sában 1991, 15-16; Berdugo 2012, 192)(4). Así lo entiende el Código Penal peruano (en adelante, "CP"), en cuyos preceptos se pueden subsumir grandes operaciones criminales, pero al mismo tiempo, hechos delictivos menos elaborados ${ }^{(5)}$, como $^{2}$ por ejemplo, la venta de un proyecto público, con adendas comprometidas a futuro y la coordinación de distintas dependencias públicas, el soborno a un agente de policía para evadir una sanción administrativa, o hasta la promesa de interceder ilícitamente ante un funcionario o funcionaria pública.

La maleabilidad del concepto de corrupción permite identificar sus características comunes en supuestos de hecho a veces lo bastante disímiles como para ser clasificarlos en una misma sección o apartado del CP. Por ejemplo, la conducta típica de colusión no pertenece a la Sección IV, Capítulo II, Título XVIII, del CP, denominado Corrupción de Funcionarios. Sin embargo, dicho precepto es vital en las investigaciones y juzgamientos que componen uno de los casos de corrupción más graves de la realidad política peruana denominado lava jato ${ }^{(6)}$. Así, la delimitación del concepto se deja ver, en este caso, desde la práctica que dispensa la magistratura.

También desde la doctrina se pueden plantear criterios de identificación, respecto, por ejemplo, de los elementos de tipicidad obligatorios en los delitos de corrupción ${ }^{(7)}$. Es más, a partir de la interacción con otras categorías criminales (Kupatadze 2015, 199) es posible identificar nuevos factores en la corrupción contemporánea, por ejemplo, su alianza casi imprescindible con la actividad empresarial. Sin embargo, cualquier sea la fuente de construcción de los dinteles del concepto penal de corrupción, este no podrá mutarse en las demás categorías con las que se relaciona o reducirlas a extensiones de sí mismo. La valía de la explicación poliédrica de la corrupción gravita, principalmente, en el intercambio de criterios de imputación que puedan funcionar indistintamente en una u otra clasificación criminal.

De acuerdo a los hechos que encabezan las investigaciones del Ministerio Público peruano ${ }^{(8)}$, se podría decir que la cotidianidad de la corrupción ha pasado de ser simples conductas de personas aprovechadas a contar con un marco sistemático y organizativo (Cigüela Sola 2016, 4; Hava García 2016, 67). Este nuevo establishment del delito se denomina gran corrupción, su fulcro es el poder político y económico, y sus contornos, la impunidad y la gran rentabilidad económica de sus acciones. Es decir, por un lado, la configuración de un marco legal ad hoc de actuación, en cuya virtud se asegure un difícil escollo para la investigación (en instancias penales y administrativas). Y por otro lado, la permanencia en la más idónea situación para delinquir, que consiste en el acceso continuado a grandes operaciones económicas, que ayudan a lograr los mejores acuerdos ilegales (Marine 2006, 215) y la maximización de sus beneficios económicos.

En virtud de los poderes involucrados, se deben precisar, además, dos características también fundantes de la gran corrupción: la pluralidad de intervinientes y el ingente

(4) Del mismo modo, Transparencia Internacional define la corrupción como el abuso del poder público en beneficio privado. Disponible en: https://transparencia.org.es/wp-content/uploads/2014/10/Gu\%C3\%ADa-de-lenguaje-claro-sobre-lucha-contra-la-corrupci\%C3\%B3n. pdf; consulta: 2-1-2019.

(5) En el actual Plan Nacional de Integridad y Lucha contra la Corrupción 2018-2021 se hace referencia a los conceptos de gran corrupción, mediana corrupción y pequeña corrupción.

(6) En términos generales, se conoce como el caso Lava Jato a la red de corrupción más grande de América Latina, que involucra a las más altas autoridades de cada país, donde ciertas empresas brasileras del rubro de la construcción (principalmente Odebrecht) pagaban sobornos para hacerse con contratos públicos millonarios, véase De Cassia Biason (2017, 63-64).

(7) Desde sus elementos fundantes, solamente el cohecho y el tráfico de influencias serían reales delitos de corrupción pública, véase De la Mata Barranco $(2016,7-8)$. En el mismo sentido, y con un razonamiento interpretativo más restrictivo que el anterior, el único delito de corrupción propiamente dicho sería el cohecho, véase Morra (2004, 99-100). Otro criterio de delimitación sería, por ejemplo, el ánimo de lucro (directo o indirecto) del funcionario o funcionaria pública, así como el daño económico al erario público, véase Correcher Mira $(2015,23)$. En el lindel de los beneficios, la ganancia ilícita sería el criterio determinante de una conducta de corrupción, véase De la Cuesta Arzamendi $(2003,8)$.

(8) El expediente judicial que mayor atención mediática ha obtenido por tratarse de personajes políticos sumamente controvertidos, Expediente No 00299-2017-46-5001-JR-PE-01, correspondiente al caso denominado cocteles, un supuesto de lavado de activos que vincularía a la lideresa del partido político “Fuerza Popular" (Keiko Fujimori). En lo que respecta al Ministerio Público, se pueden citar las siguientes investigaciones: Carpeta Fiscal No. 06-2015 (IIRSA y Huachipa), Carpeta Fiscal No. 07-2016 (Empresa Camargo Correa), Capeta Fiscal No. 14-2016 (Tramo IV IIRSA SUR), Carpeta Fiscal No. 19-2016 (Odebrecht), entre otros casos. 
Aproximación teórica sobre la aplicación de la autoría mediata por dominio de aparato organizado de poder en supuestos de gran o alta corrupción

A Theoretical Approach to the Application of Command Responsibility for Domain over Organized Power Structures to High Corruption Cases

daño económico que se produce (Rose-Ackermann 2001, 5; Kaufmann 2000, 368; Mauro 1995, 683, 704; Lopes Junior y otros 2018, 699).

En consecuencia, el vórtice de lo que significa la gran corrupción se compone del sistema democrático y los fines prestacionales del Estado de Derecho, que soportan en última instancia sus graves consecuencias, a costa de su población más vulnerable (Klitgaard 1988, 47) ${ }^{(9)}$.

De forma pormenorizada, el andamiaje de la gran corrupción no podría edificarse sin la participación del poder político, que descansa en manos de quien se ubica en el ápice de la Administración (Zúñiga Rodríguez 2012, 32). Por ejemplo, si se trata de la desviación en la aplicación de recursos públicos, quien tenga el máximo poder de disposición jurídica de los caudales o efectos administrados será quien esté situado en el más alto puesto del organigrama de la entidad pública responsable. Disponibilidad que se desprende de una facultad política y discrecional alejada, normalmente, de la operatividad concreta, y, casi siempre, resguardada en el Poder Ejecutivo. En lo que interesa para un cohecho, lo más eficiente será sobornar a quien, en última instancia, pueda resolver a favor del interés de quien paga. Lo mismo ocurre respecto de la corrupción presente en los contratos públicos o cualquier operación económica a cargo del Estado, pues será el más alto funcionario o funcionaria pública quien tenga el monopolio de decisión en la aplicación de los recursos públicos, y en esa condición, el poder para asegurar los intereses ilegítimos de una concertación corrupta.

Como consecuencia lógica de su mayor poder, los altos mandos del aparato público suelen participar en el hecho delictivo con decisiones políticas más que ejecutivas, entonces, a medida que se descienda en el organigrama de la Administración, las infracciones de deberes o competencias de funcionarios y funcionarias desvelarán, cada vez con mayor grado de exactitud, el plan criminal. Si el ápice del organigrama está más alejado, normativa y fácticamente, del hecho delictivo, quiere decir que se necesita de un esfuerzo considerable en la investigación, si se intenta imputarle responsabilidad penal (Olásolo 2013,189).

El poder político tiene un símil económico en la criminalidad de alta o gran corrupción, llegando incluso a presuponerse (Terradillos Basoco 2017, 4).Solamente los mejor posicionados en el mercado económico están en condiciones de participar como aptos socios estratégicos. Y lo harán, fundamentalmente, a través de la actividad empresarial, no solamente porque ella asegura la disposición de los recursos suficientes, tanto técnicos, como patrimoniales, sino porque, en muchas ocasiones, la estructura organizada de una empresa puede servir como coraza de impunidad a favor de sus altos dirigentes (Cingari 2011, 23).

La sinergia de ambos poderes, el político y el económico, da cuenta, principalmente y en lo que interesa en esta tesitura, del nivel de organización requerido. La distribución coordinada de tareas, de un lado, reduce el grado de dificultad de la comisión (Mcintosh $1977,15)$ y, de otro, incrementa los costos de captura o investigación (impunidad) ${ }^{(10)}$; pues cuando una sola persona monopoliza todas las acciones criminales, su captura supone, en paralelo, el fin de todas ellas. Por lo demás, la criminalidad organizada no representa únicamente mayor idoneidad lesiva contra bienes jurídicos (Terradillos Basoco 2016, 39 ), sino que produce mayores réditos económicos, elemento centrípeto de esta modalidad delictiva (Di Gennaro 1993, 7-12), que se trasluce con mayor claridad, cuando de delitos de corrupción se trata.

El crimen organizado como herramienta de ejecución de la gran corrupción, también se explica desde cualidades de operatividad. La distribución de competencias normativas, que es transversal en el sistema burocrático de la Administración, impide que una sola persona esté en capacidad de ejecutar el delito, empero, dicha aparente limitación, realmente supone una ventaja de eficacia. Por ejemplo, para el caso de gran corrupción en contratos públicos de infraestructura, supuesto altamente sensible a la corrupción (Fernández Teruelo 2015, 55), el o la Presidente no podría cumplir el compromiso adquirido con un empresario, sin hacer flagrante la ilicitud de su conducta, si no cuenta con la sociedad del Ministro o Ministra del sector y del responsable de la oficina que licitará la obra pública. Es decir, el entramado de competencias al interior de la Administración es el espacio óptimo para crear un sistema coordinado en la ejecución del delito.

(9) “(...) La corrupción perturba gravemente el funcionamiento de las instituciones del Estado conforme a sus principios básicos de funcionamiento, en particular, conforme a los principios de igualdad, legalidad y eficiencia (...)", Sánchez García de Paz (2008, 457).

(10) En términos generales, las características que dan forma a la organización criminal tienden a asegurar impunidad de sus actividades y de sus miembros, véase Méndez Rodríguez $(2014,520)$. 
Por lo demás, la criminalidad organizada tiene un efecto corruptor (Zúñiga Rodríguez 2002, 53) o busca espacios corruptos (Iglesias Río 2001, 1447; Sánchez García de Paz 2008, 456), y esto es así porque la criminalidad organizada requiere de la corrupción para materializar sus propósitos ${ }^{(11)}$. Para funcionar al margen de la ley y contar con la connivencia de las autoridades, los personajes a sobornar están plenamente identificados (por su ubicación en el organigrama administrativo) y en condiciones de asegurar que los demás no entorpecerán las actividades delictivas (por el poder administrativo que poseen sobre sus subordinados). Condiciones estas que abaratan los costos de funcionamiento del crimen organizado(12) (trata de personas, tráfico ilícito de drogas, blanqueo de capitales o lavado de activos, etc.).

\section{Aparato organizado de poder y organización criminal}

Según lo dicho hasta aquí, el concepto criminológico de gran corrupción hace referencia a determinadas características de la criminalidad organizada, pero ello no significa la reducción de los escenarios a uno solo: la existencia de una organización criminal dedicada a cometer delitos de corrupción. Y aunque dicho supuesto amerita una investigación teórica y práctica minuciosa (principalmente porque se trata de una explícita previsión legislativa del ordenamiento penal peruano(13)), aquí se intenta llamar la atención sobre los factores criminológicos concernientes a la organización, que complementan la existencia de un supuesto de gran corrupción, y que permite vincular el análisis a la aplicación de la teoría de la autoría mediata por dominio de organización.

Las organizaciones criminales, ejemplos de criminalidad organizada, son hoy en día una de las preocupaciones más importantes de la comunidad jurídica internacional (Villegas 2018, 51; Escalante-Barreto 2017, 103), precisamente por las características que su actividad deja ver en cada uno de los espacios delictivos donde actúa(14): tráfico de armas, trata de personas, tráfico de migrantes, etc. Niveles de extensión (Zúñiga Rodríguez 2002, 54 y 56), infiltración en sistemas legales y políticos del Gobierno, contacto con distintos instrumentos de actuación como negocios o estructuras comerciales (González Más 2012, 147), etc., son elementos que explican su finalidad lucrativa(15),y su idoneidad lesiva contra bienes jurídicos; modus operandi que les ha valido una autónoma tipificación penal, con ciertos matices $^{(16)}$.

Los requisitos del crimen organizado (género de la especie organización criminal) pueden exigir estructuras piramidales, posiciones jerarquizadas y división de tareas (González Más 2012, 149), pero no se trata de condiciones excluyentes. Así da cuenta el artículo 2 de la Convención de las Naciones Unidas contra la Delincuencia Organizada Transnacional, que a la letra dice:

“a) Por grupo delictivo organizado se entenderá un grupo estructurado de tres o más personas que exista durante cierto tiempo y que actúe concertadamente con el propósito de cometer uno o más delitos graves o delitos tipificados con arreglo a la presente Convención con miras a obtener, directa o indirectamente, un beneficio económico u otro beneficio de orden material (...)

c) (...) Por grupo estructurado se entenderá un grupo no formado fortuitamente para la comisión inmediata de un delito y en el que no necesariamente se haya asignado a sus miembros funciones formalmente definidas ni haya continuidad en la

(11) Así lo entiende además la Convención de Naciones Unidas contra la Corrupción, en su Preámbulo.

(12) Por ejemplo, una red de trata de personas incurriría en altos costos para trasladar a las víctimas del delito de una zona rural a una urbana si tendría que montar una fachada que despiste a los agentes de policía que custodian las carreteras. Sin embargo, contando con el sistema corrupto, bastará con sobornar al jefe de la sección territorial, para que los retenes policiales del camino no exijan la documentación de los menores de edad o la acreditación de los fines del viaje.

(13) Ley 30077, Ley Contra el Crimen Organizado, artículo 3.19.

(14) Sobre las características de la delincuencia organizada y sus formas de actuación, véase Pérez Cepeda (2004, 13-16).

(15) La complejidad de una organización criminal va en aumento, hasta adquirir un carácter transnacional, véase Zúñiga Rodríguez $(2016,81)$.

(16) El Código Penal español, por ejemplo, dentro del Título XXI "delitos contra la Constitución", Capítulo IV "de los delitos relativos al ejercicio de los derechos fundamentales y libertades públicas", sanciona a las asociaciones ilícitas en el artículo 515. Luego, en el Título XXII "delitos contra el orden público", Capítulo VI "de las organizaciones y grupos criminales", el mismo cuerpo normativo sanciona a la organización criminal en su artículo 570bis. En ambos casos se hace referencia a un nivel de organización importante con efectos de cometer delitos. Sin embargo, el artículo 570 bis prevé específicamente el nivel de coordinación y el reparto de tareas. Y en este sentido se puede afirmar que existe una gradación de complejidad en la organización, a nivel de tipicidad, entre una asociación ilícita para delinquir y una organización criminal. 
Aproximación teórica sobre la aplicación de la autoría mediata por dominio de aparato organizado de poder en supuestos de gran o alta corrupción

A Theoretical Approach to the Application of Command Responsibility for Domain over Organized Power Structures to High Corruption Cases

condición de miembro o exista una estructura desarrollada (...)".

Como puede apreciarse, el concepto es amplio, y esa podría ser la razón por la cual algunas codificaciones penales legislan en clave de gradualidad, el nivel de organización requerido para cometer delitos ${ }^{(17)}$ (organizaciones criminales o asociaciones ilícitas para delinquir). Pero a pesar de sus distintos reproches, la actuación criminal en conjunto siempre se sanciona desde la base de un grupo de personas que tienen una finalidad común ${ }^{(18)}$, es decir, una pluralidad de sujetos "(...) sin ninguna cohesión que vaya más allá de que 'todos desean lo mismo"” (Kiss 2013, 11).

El criterio fundamental de una organización criminal es, al mismo tiempo, el complemento criminológico de la gran corrupción. Señaladamente, es la estructura criminal como eje central de imputación en la criminalidad organizada ${ }^{(19)}$ aquello que termina de describir la tipología de corrupción que aquí se comenta. De esta manera, los poderes político y económico habrán de funcionar de manera coordinada (Villegas Díaz $2018,61)$, probablemente captando a más de una Institución o varias entidades de la misma, con el objetivo de desarrollar complejas estrategias delictivas, en base a la importancia de sus protagonistas, sus recaudos de impunidad y el daño económico que se desprende de sus entrañas.

La importancia de la estructura organizativa se deja notar claramente en la legislación penal peruana sobre la materia. La Ley 30077, Ley Contra el Crimen Organizado, supone una agravante al clásico delito de asociación ilícita para delinquir, exigiendo inequívocamente para ello, coordinación y concertación en la actuación de los miembros de la organización criminal ${ }^{(20)}$.

No obstante, y a pesar de la importancia del estudio del injusto de organización, la autoría mediata por dominio de un aparato organizado de poder no necesita de la existencia de una organización criminal o una asociación ilícita para delinquir, como plataformas típicas y previas que ciernan sus postulados. Dicho criterio de imputación (Ambos 2005, 141) puede poner en relación directa el injusto de organización con el delito concreto llevado a cabo por la organización, pero esto es una más de sus bondades, no un supuesto indispensable de su aplicación. Entonces, un aparato organizado de poder, como su nombre lo indica, es una forma organizada de delinquir, pero no una organización criminal; no se trata de conceptos equiparables. La escisión que se apunta tiene sobradas razones de ser, y algunas de ellas se comentan a continuación.

La teoría de la autoría mediata por dominio de organización tiene su principal antecedente histórico en casos de criminalidad estatal (nuestra experiencia judicial así lo demuestra en las sentencias contra Abimael Guzmán y Alberto Fujimori(21)(22), mientras que la llamada criminalidad organizada es un concepto que identificaría a toda organización no estatal (Bolea Bardón 2000, 338).

En particular, una organización criminal se crea expresamente para delinquir. Un aparato de poder es una estructura previa que el hombre de atrás encuentra y utiliza (Aboso 2012, 302): se trata de un sistema de justicia formalmente constituido, cuya cúspide hace uso del mismo para generar una injusticia del sistema (Ambos 2005, 79$98,94)$. Es más, una organización criminal jamás podrá equiparse a un órgano público, menos a un partido político, de acuerdo a la uniformidad de la judicatura peruana ${ }^{(23)}$. $Y$ en el caso de la tesis objeto de estudio, existe un calco criminal de la propia estructura de

(17) En algunas ocasiones las respuestas político criminales tienden a ser desproporcionales, simbólicas y erráticas, véase Terradillos Basoco (2016b, 20-21).

(18) Característica que está recogida expresamente en el artículo 25.3.d), del Estatuto de Roma de la Corte Penal Internacional.

(19) Acuerdo Plenario No. 01-2017-SPN, Sala Penal Nacional y Juzgados Penales Nacionales, de fecha 5.12.2017, fundamento 7. En el mismo sentido, véase Cordini, (2017, 340).

(20) Acuerdo Plenario No. 01-2017-SPN, cit., fundamentos 9, 12, 16 y 18.

(21) La Sala Penal Nacional, Expediente: A.V. 19-2001, de fecha 7 de abril de 2009, sentenció a Alberto Fujimori a 25 años de prisión por los delitos de secuestro agravado, lesiones graves y asesinato, utilizando la tesis de la autoría mediata por dominio de organización, pp. 653-657. Y la misma imputación pesó sobre Abimael Guzmán, por los delitos de terrorismo agravado y homicidio calificado, véase Sala Penal Nacional, Exp. Acumulado No. 560-2003, cit., p. 170.

(22) La tesis de Roxin tomó como ejemplo el caso juzgado, en primera instancia, por la Corte Distrital de Jerusalén, contra el ex SS (Schutzstaffel) Otto Adolf Eichmann. De hecho, Kai Ambos $(2015,79)$ habla de Burocracia Nazi de destrucción. Y dicha teoría hace referencia a supuestos más complejos que el descontrol de las conductas de los subordinados al que, aparentemente, haría referencia el artículo 28 del Estatuto de Roma de la Corte Penal Internacional.

(23) Acuerdo Plenario No. 01-2017-SPN, cit., fundamento 22.

(24) Ibídem., fundamento 21. 
la administración pública, es decir, se utilizan sus cauces para el tránsito de un plan criminal de corrupción.

Una organización criminal puede estar estructurada de forma vertical, horizontal o adaptarse a formas flexibles de jerarquía ${ }^{(24)}$. Mientras que un aparato organizado de poder se construye y funciona, principalmente, de forma vertical ${ }^{(25)}$, es esa dirección la que permite postular cada uno de sus requisitos, como se tendrá oportunidad de exponer infra.

La coautoría es el título de intervención por excelencia en una organización criminal o asociación ilícita para delinquir (Faraldo Cabana 2004, 304), mientras que en un aparato de poder (donde la autoría mediata es el cenit) solamente es admisible entre quienes ostentan un mismo grado de poder y mando (Ambos 2005, 94).

Otro matiz importante se encuentra en la tipificación concreta $^{(26)}$ (sea como asociación ilícita u organización criminal); no existe, por lo menos en el Perú, el delito que tipifica la existencia de un aparato organizado de poder (en clave de la tesis doctrinal que aquí se comentará). Para decirlo en otros términos, la autoría mediata no es un delito, es un criterio de imputación, y como tal se distingue de la autonomía típica de los delitos de organización criminal o asociación ilícita para delinquir, donde se busca atribuir el injusto de organización a sus miembros, y donde tiene cabida la teoría de la autoría mediata, cuando de imputar los llamados delitos fin se trate.

Por lo demás, reconocer los distintos componentes entre el delito de organización criminal y un aparato organizado de poder podría producir consecuencias positivas, respecto de la actuación del Ministerio Público. Es decir, si no se requiere probar la existencia de una organización criminal para imputar responsabilidad penal contra un superior jerárquico, la autoría mediata por dominio de organización se yergue como una alternativa eficiente en el proceso penal sobre casos de corrupción altamente estructurados, donde son precisamente los superiores jerárquicos de la administración pública, los que suelen salir bien librados del proceso, sin que dicha fortuna (aparentemente injusta) suela sonreírles a sus directos subordinados en el aparato público.

Y a favor de esta premisa se argumentará en lo que sigue, con ideas, por supuesto, absolutamente discutibles y llanas al debate.

\section{Sobre los fundamentos y legitimidad de la tesis del autor mediato por dominio de organización o aparato de poder}

Se trata de "(...) otra manifestación del dominio del hecho que hasta ahora no ha sido mencionada ni siquiera por la doctrina ni por la jurisprudencia (...)"(27), decía Roxin $(2000,270)$ para referirse a lo que él denominó "dominio de la voluntad en virtud de estructuras de poder organizadas"; aunque de novedosa, por lo extenso de los estudios y aplicaciones jurisprudenciales, poco le queda a esta tesis (Aboso 2012, 280; Roxin 2006, 242).

La teoría mencionada tiene la siguiente hipótesis: “(...) el sujeto de atrás tiene a su disposición una "maquinaria" personal (casi siempre organizada estatalmente) con cuya ayuda puede cometer crímenes sin tener que delegar su realización a la decisión autónoma del ejecutor" (Roxin 2000, 270). Por ende, el hombre de atrás puede ser autor mediato, aun cuando los ejecutores inmediatos sean autores directo (Roxin 2006, 242; 2000, 160). Desde su primigenio planteamiento, la organización tiene vida propia, funciona automáticamente; el sujeto de atrás confía en la ejecución de su orden, porque el ejecutor es cambiable a voluntad, es anónimo y sustituible (Roxin 2000, 272-273).

Se habla de un modelo de imputación donde el actuar último no tiene el único interés del Derecho Penal, y tampoco es el más relevante (Peñaranda Ramos 2008, 162). Con este planteamiento se rompe la regla según la cual “(...) la autoría mediata no es, pues, posible en la actuación delictiva (dolosa y culpable) del ejecutor (...)" (Jakobs 1997, 763), apelando, para ello, a la variedad de contenidos que la autoría puede albergar en el razonamiento penal (Górriz Royo 2008, 419).

(25) Dice la sentencia contra Alberto Fujimori: “(...) Ésta [haciendo referencia al aparato de poder] posee una línea jerárquica sólida que hará responsable su nivel estratégico superior por las decisiones y designios con carácter delictivo que a su interior se adopten. Los cuales, luego, e serán asignados al ejecutor inmediato por la vía de la verticalidad (...)", Sala Penal Nacional, Expediente: A.V. 19-2001, cit., página 633, y vuelve a afincar su razonamiento en la verticalidad, cuando habla de los tipos de mandos que sustentan la responsabilidad del autor mediato, en el marco del funcionamiento de Sendero Luminoso, p.635. En el mismo sentido, véase Olásolo $(2013,192)$.

(26) “(...) la asociación, como entidad criminosa, termina por separarse netamente de los singulares delitos que constituyen su propósito (...), véase Grisolía (2004, 76). De hecho, el pertenecer a una asociación es un injusto de mera actividad (Grisolía 2004, 84).

(27) Con un ligero resumen de los principales fundamentos de la teoría, véase Rusconi y otros (2011, 25-28). 
Aproximación teórica sobre la aplicación de la autoría mediata por dominio de aparato organizado de poder en supuestos de gran o alta corrupción

A Theoretical Approach to the Application of Command Responsibility for Domain over Organized Power Structures to High Corruption Cases

Decir que es tan autor quien mata a alguien, como quien da la orden de hacerlo desde una posición alejada del evento criminal, e incluso distante de las decisiones concretas del atentado, como tiempo, lugar, modalidad, etc., supone la construcción de una base metodológica que permita explicar una forma de instrumentalización, que armonice el planteamiento con el principio de responsabilidad ${ }^{(28)}$.

Sin que sea la única forma de atribución de responsabilidad penal contra el superior jerárquico en un aparato organizado (Meini 2007, 52), y con un consenso importante en la doctrina, los principales requisitos de la autoría mediata por dominio de organización se pueden resumir en la disposición de los miembros a ejecutar las órdenes, su subordinación (que implica la existencia del mando en un aparato de poder), su fungibilidad (Bolea Bardón 2000, 396) y, principalmente, la automaticidad del aparato, tal como se detalla a continuación.

\subsection{Existencia de un aparato organizado de poder}

Un aparato de poder supone una estructura vertical y piramidal (Meini 2008, 31), en cuya cúspide se ubican los órganos o mandos directivos que toman las decisiones e imparten órdenes y por debajo, los encargados de cumplirlas, que no participan en la creación de los planes y se limitan únicamente a cumplir su parte (Bolea Bardón 2000 337). Señaladamente, existe una estructura preestablecida (Roxin 2000, 244), donde "(...) sólo hace falta que participen unas cuantas personas (...)" (Roxin $2000,275)$, que funciona de forma independiente de la voluntad de los ejecutores materiales y está sometida a la voluntad del hombre de atrás.

La composición y dinámica del aparato, que subyace a sus miembros (Meini 2008, 32), permite que “(...) la iniciativa de puesta en marcha por el sujeto de detrás se realiza con independencia de la persona del ejecutor" (Roxin 2000, 278). Por ende, "(...) autor mediato sólo puede ser quien dentro de una organización rígidamente dirigida tiene autoridad para dar órdenes y la ejerce para causar realizaciones del tipo (...)" (Roxin $2000,244)$. Pero, “(...) no cualquier tipo de autoridad es la que aquí interesa, sólo aquella que le permite al sujeto ordenar la comisión de hechos antijurídicos" (Meini 2008, 31 y Faraldo Cabana 2004, 205). Y desde esta concepción, los mandos medios o intermedios, que porten el poder de dictar una orden también serán considerados autores mediatos (Roxin 2009, 59).

Las características señaladas pueden resumirse en la automaticidad del aparato de poder (Meini 2008, 33), esto es, si la ejecución de la orden delictiva no requiere de la intervención directa del sujeto de atrás, sino que son los propios engranajes del aparato (a cargo de distintas personas) los que la llevan a cabo, eso quiere decir que el funcionamiento del aparato, desde la posición del sujeto de atrás, es automático. Así, lo instrumentalizado es el aparato de poder (Roxin 2009, 58), no el ejecutor material (Hernández Plasencia 1996, 275), y la esencia de un aparato de poder se definirá desde sus puntos más distantes $^{(29)}$. Y a partir de esta premisa, la clásica instrumentalización por error o coacción pierde relevancia en el debate.

Sin embargo, para un sector doctrinal, decir que el sujeto de atrás realiza el delito por medio de la organización y no necesariamente a través del ejecutor fungible es un planteamiento que se enfrenta derrotado a la premisa de la Parte General del Código Penal que habla de comisión a través de otro, para referirse a una persona y no a una organización (Faraldo Cabana 2008, 121; 2004, 114)(30). Empero, esta aparente contradicción se solucionaría considerando que el vocablo instrumento debe ser entendido en términos generales, siendo lo decisivo que se pueda indicar que tanto el hombre de atrás como el ejecutor material comparten el dominio del hecho (riesgo típico), desde fundamentos distintos, claro está; el primero desde la propia dinámica de la organización, el segundo, desde su decisión autónoma de cumplir (o no) con una orden (Bolea Bardón $2000,367-368$ y 374$)$.

(28) De acuerdo a un sector de la doctrina, la tesis de la autoría mediata por dominio de organización abandona el principio de responsabilidad, véase Schünemann (2004, 35-36). Las formas de autoría mediata no explicarían cómo el sujeto es responsable por el hecho, sino solamente el planteamiento esquemático del problema (página 646); por ejemplo, en la autoría mediata a través de un instrumento doloso no cualificado, tradicionalmente, se dice que el instrumento no puede ser autor, pero no se dice por qué el sujeto de atrás deba serlo (página 618); de igual modo, la tesis de la autoría mediata no termina de explicar en qué medida la fungibilidad es un dato suficiente, véase Díaz y García Conlledo (1991).

(29) Por lo demás, las razones de adhesión al aparato, así como la forma de haber logrado el ápice de la misma no tienen relevancia a efectos de sustentar esta teoría.

(30) De hecho, podría alegarse que una organización criminal no tiene una personalidad jurídica reconocida, por ejemplo, no puede incorporarse como tercero civil responsable en un proceso penal. 


\subsection{Funcionamiento de la organización al margen del Derecho}

Dice Roxin: "El sistema (o sea, el sistema parcial de un Estado) tiene, por tanto, que trabajar delictivamente como un todo (desvinculado del Derecho) [rechtsgelöst] si la seguridad del resultado que fundamenta una autoría mediata debe atribuirse a las instrucciones de los hombres de atrás" (2006, 245). Dicho en otros términos, la orden de cometer delitos no puede fundamentar dominio, allí donde la organización se mueva por los cauces del Derecho (Roxin 2000, 277).

El requisito de apartamiento del Derecho no significa que todo el aparato funcione al margen del mismo (Meini 2008, 47; Faraldo Cabana 2004, 198), sino que basta con que funcione desvinculado de la Ley, en función del delito ordenado (Roxin 2009,60 ), pero además, en función de los objetivos, métodos y medios de la propia organización (García Cavero 2009, 601). En consecuencia, en un solo aparato organizado podrán convivir en paralelo dos formas de funcionamiento, una sujeta a la legalidad, y la otra no. La segunda, asegura al sujeto de atrás que su orden transite a lo largo de la organización, hasta cumplirse. Objetivo imposible en la primera modalidad (Faraldo Cabana 2008, 110).

Este segundo requisito tiene dos manifestaciones típicas: i) organizaciones del propio aparato estatal y ii) organizaciones clandestinas o secretas (Roxin 2000, 277-278). Las segundas, por los adjetivos usados, suelen estar totalmente al margen del Derecho, es decir, su constitución no tiene otra explicación que la comisión de delitos. Sin embargo, y especialmente cuando de aparatos estatales se trata, afirmar la total marginalidad legal es algo de muy difícil contrastación, pues incluso en el gran aparato de poder Nazi, algún acto legal debió acontecer. Con lo cual, la ilegalidad se refiere, únicamente, a que la orden del superior jerárquico se aparta del Derecho. Pero de por sí esto es algo que comparten todos los delitos (Meini 2008, 54; Marín de Espinosa Ceballos 2002, 90), por ende, quizá el requisito de la marginalidad del Derecho como soporte del dominio del aparato de poder a manos del hombre de atrás no sea tal, sino que únicamente sirva para la descripción de los objetivos delictivos del aparato (que paradójicamente nace en virtud de la ley).

Por lo demás, que los integrantes de la organización se vinculen a través de órdenes ilícitas realmente describe su disposición a cometer delitos, como pieza fundamental de la autoría mediata por dominio de aparato de poder (Marín de Espinosa Ceballos 2002, 60).

\subsection{Fungibilidad del ejecutor material}

La fungibilidad del ejecutor material aseguraría, en gran medida, el cumplimiento de la orden ilícita proveniente del sujeto de atrás (Roxin 2009, 58-61; 2000, 272; Cervini $2005,148)$, es decir, que los miembros del estrato inferior del aparato sean fácilmente sustituibles probaría que la organización funciona independientemente de la identidad variable de sus miembros (Bolea Bardón 2000,348 ). La presencia de muchos posibles ejecutores no es una presunción hipotética si tomamos en cuenta las características propias de la organización (Roxin 2006, 245). Parte de la complejidad del aparato de poder se explica por la multiplicidad de ejecutores materiales (como toda forma de organización, la base de la pirámide siempre es más ancha $\left.{ }^{(31)}\right)$, sin que ello suponga, no obstante, exigir un número ilimitado de personas dispuestas al hecho (Bolea Bardón 2000, 396). Entonces, un elemento fundante del dominio del hecho sería la seguridad del hombre de atrás de que la organización proveerá de un ejecutor más dispuesto, cuando el inicial se desista.

Este requisito tiene mucho sentido si se define a la organización como una estructura vertical de poder (Meini 2008, 113; Faraldo Cabana 2004, 97), donde el ejecutor no puede evitar con su negativa la realización del delito, a lo sumo puede anular su aportación (Faraldo Cabana 2004, 94). Y de esta constatación se desprende, que mientras más alto se escale, menos fungibilidad se encontrará en el aparato (Aboso 2012, 304), pues no solamente no parece lógico que existan más mandos intermedios que obedientes ejecutores, sino que el poder que ostentan los mejor posicionados en la pirámide, no es un bien accesible a todos. En efecto, la teoría que se comenta fue pensada principalmente para aparatos estatales que aprovechan su poder para cometer delitos (Faraldo Cabana $2004,31)$ y si atendemos al carácter político de la composición estatal, es claro que solo se elige a un presidente, a una jefa de oficina o a un responsable de la gestión, con lo cual, pocos optan por el poder de mando superior 0 intermedio. De esto resulta que, si un mando intermedio de importante jerarquía se negase a cumplir la orden, el sujeto de atrás perdería el dominio del hecho, porque de ese escaño no se predicaría la fungibilidad.

(31) Parece obvio que se trata de un número considerable de personas, véase Aboso $(2012,335)$. 
Aproximación teórica sobre la aplicación de la autoría mediata por dominio de aparato organizado de poder en supuestos de gran o alta corrupción

A Theoretical Approach to the Application of Command Responsibility for Domain over Organized Power Structures to High Corruption Cases

Cabe señalar, que el aparente desdén por el anónimo y cambiable ejecutor material, "(...) ruedecilla en el engranaje (...) (Aboso 2012, 283), no se refleja en los fueros del Derecho penal, pues allí se le considera tan autor, como al poderoso sujeto ubicado en la cima de la organización (Faraldo Cabana 2004, 104) $)^{(32)}$.Es más, la fungibilidad del ejecutor material explicaría la relevancia del aparato desde sus puntos más distantes, pues ella aseguraría que la orden será cumplida (Roxin 2009, 58 y 61).

A pesar de lo indicado, podría no ser tan cierta la relevancia de este requisito. Que los ejecutores materiales sean sustituibles, no siempre representa una alta probabilidad de que el delito ocurra (Faraldo Cabana 2004, 90), pues la capacidad de reemplazo es muestra de condiciones logísticas óptimas al interior de la organización, no de la destreza requerida para cometer el delito (capacidad de convencimiento del esbirro, para lograr aportantes fantasmas durante una campaña electoral, por ejemplo). Además, la fungibilidad no explica cómo o a través de qué mecanismo es que un sujeto ejecutor reemplaza a otro que falló o que simplemente abdicó de obedecer la orden.

La valía de este requisito solamente podrá constatarse cuando realmente alguien desista de ejecutar la orden, supuesto que no debería ser recurrente en un aparato de poder (Meini 2008, 39-40; Roxin 2009, 64), que principalmente se construye para transmitir y ejecutar órdenes. Sustituir rápidamente al autor del yerro tampoco es muestra de automatismo, lo es que el aparato encuentre la forma de cumplir la orden, y ello se puede lograr sin cambiar de ejecutor, antes bien, dándole una segunda oportunidad, sin que el sujeto de atrás lo sepa. $Y$ es que centrar el análisis en lo fungible de los miembros del aparato desprecia el valor de las habilidades, destrezas y competencias (a veces normativas) de los ejecutores enfilados para llevar a cabo el plan criminal.

En definitiva, probablemente la fungibilidad realmente signifique que el aparato cuente con el personal suficiente, resuelto y con los recursos necesarios para cumplir la orden, frente a determinadas eventualidades (miedo del ejecutor, torpeza, intervención policial, etc.), sea que trate de miembros menos o más fungibles.

\subsection{Disposición a cometer el delito por parte de los miembros del aparato}

Para que una orden ilícita se traslade desde la cúpula de una organización hasta sus estratos ejecutores, y sea cumplida, sus miembros tendrán que estar de acuerdo y concurrir con su realización, algo que parece obvio tomando en consideración que la incorporación al aparato de poder es un acto voluntario. Así se explicaría que los engranajes del aparato de poder funcionen de forma automatizada, esto es, sin que el emisor de la orden deba participar activamente calibrando su decisión a lo largo de la estructura vertical.

Contando con la disposición de los miembros a cometer el delito, cada nivel de la organización informará al siguiente acerca de la orden emitida, produciendo que los extremos de la distribución jerárquica no tengan contacto, por lo menos respecto de la coordinación y ejecución del plan criminal. Y tal vez esta descripción explique cómo cada quien se vincula con la orden y es autor autónomo (y no coautor ${ }^{(33)}$ ) del delito ordenado desde la cúpula de la organización. Pero, además, quizá también así se explique cómo funciona un aparato de poder que se constituye a expensas de una organización legal previamente establecida, como es el caso de la Administración, en referencia a delitos de corrupción pública.

Cualquiera sea la razón de la sujeción a las reglas del aparato de poder ${ }^{(34)}$, lo cierto es que la especial disposición de los ejecutores materiales fundamenta la seguridad del hombre de atrás respecto de la ejecución de sus órdenes (Roxin 2006, 247).

Sin embargo, para Gustavo Aboso hablar, al mismo tiempo, de una especial disposición al cumplimiento y de la fungibilidad de los ejecutores resulta contradictorio, pues si un ejecutor material se negase a actuar (y otro lo reemplazaría) demostraría, por el contrario, su poca disponibilidad para cometer el delito $(2012,289-290$ y 349$)$. Por ende, la congruencia de ambos elementos en una misma tesis no resulta sostenible. No obstante, y a pesar del orden lógico de la

(32) Sin embargo, para Bolea Bardón (2000, 350-352), Roxin abandona el principio de responsabilidad al obviar la plena responsabilidad del ejecutor material como límite, abriendo una nueva categoría de autoría mediata.

(33) Las categorías de autoría y participación fueron construidas en torno a un hecho individual, entonces, un supuesto de pluralidad de personas organizadas jerárquicamente, de plano, escaparía a sus alcances conceptuales. La estructura ordinaria de la responsabilidad individual no captura adecuadamente la naturaleza especial de la macro criminalidad, véase Aboso (2012, 91-92); Bolea Bardón (2000, 366); Faraldo Cabana (2008, 89).

(34) Sobre que el ejecutor, dentro del aparato, se hallará expuesto a una serie de influencias, véase Meini (2008a, 28); Roxin (2009, 64) 
crítica, probablemente su fundamento parta de una confusión de planos en la imputación. Es decir, los requisitos del dominio del hombre de atrás tienen que ver con la existencia y automaticidad de la organización, allí caben la especial disposición y la fungibilidad. Luego, la relación entre el delito y su ejecutor material es un asunto de otro dominio (autoría inmediata) y allí la crítica tiene sentido, nadie que se niegue a actuar está especialmente dispuesto a hacerlo. Pero incluso desde este acierto de la crítica, quien se niegue a cometer el delito estuvo dispuesto (inicialmente) a cometerlo y, además, podrá ser sustituido por otro, y estas son cuestiones que se discuten respecto del aparato de poder. Tan distintos son los planos, que la negativa de ejecución puede solucionarse con reglas jurídicas individuales (no relacionadas al aparato), como por ejemplo, el desistimiento ${ }^{(35)}$.

Con todo, el automatismo del aparato explica la responsabilidad penal por un acto que fácticamente realizó otra persona (Hernández Plasencia 1996, 272; Sánchez-Vera 1998, 333). El principio de responsabilidad por el propio hecho no significa la imposibilidad de atribuir hechos ajenos a una persona, sino la imputación objetiva y subjetiva de esos hechos (Faraldo Cabana 2004, 105), y la tesis de la autoría mediata por dominio de organización es una herramienta idónea para dicha cuestión, pues en definitiva, el hombre de atrás controla o domina el resultado típico a través del aparato (Marín de Espinosa Ceballos 2002, 63).

\section{Aplicación de la tesis de autoría mediata por dominio de organización a casos de gran corrupción}

Fue un supuesto de hecho donde el Estado utilizó su poder para actuar contra los intereses de los ciudadanos, en el que la tesis de la autoría mediata por dominio de organización se aplicó(36).Y la corrupción pública, que básicamente entorpece el ejercicio de derechos fundamentales de las personas, representados principalmente en sus derechos económicos, sociales y culturales (Burneo 2009, 337, 342, 344; Matellanes 2012, 277-278; Asua 1997, 19; Berdugo 2012, 184), no es un supuesto diferente, es decir, también representa una actuación contra los intereses de los ciudadanos, en tanto desnaturaliza la legitimidad de una Institución, cuya existencia solamente es reconducible a los fines prestacionales de un Estado de Derecho( ${ }^{(37)}$. Para decirlo en otros términos, la expresión más lesiva de la corrupción se debe, principalmente, al involucramiento de los más altos mandos políticos, que pueden optar por decisiones, maniatadas por el soborno, que perjudiquen a grandes sectores de la sociedad, que por serlos, casi siempre son también los menos favorecidos. Las decisiones políticas que solamente benefician a un grupo reducido de personas realmente pervierten los objetivos constitucionales del Estado y con ello, menguan las condiciones de participación y desarrollo en libertad que, por lo demás, es el espíritu de nuestro modelo de organización social.

Si “(...) la gran corrupción posee contornos en buena parte coincidentes con los del crimen organizado (...)" (Hava García 2016, 67), si, además, "(...) la autoría mediata por dominio de organización reclama que se le emplee si concurren sus requisitos" (Meini 2008a, 30)(38) y aunque "(...) no todos los delitos provocados por una organización delictiva fundamentan eo ipso una autoría mediata de los que ordenan (...)" (Roxin 2006, 246), aquí se postula que los superiores jerárquicos de la Administración pueden ser procesados judicialmente bajo los alcances de la tesis de la autoría mediata por aparato de poder o dominio de organización, cuando de hechos de gran corrupción se trate.

Como se comentó supra, la legislación penal peruana considera, atendiendo al rótulo de su codificación, como delitos de corrupción, las siguientes conductas: cohecho (y sus distintas modalidades), tráfico de influencias y enriquecimiento ilícito, pero además, podrían tener el mismo marbete, la colusión, el peculado (y sus variantes), la negociación incompatible, el patrocinio ilegal, la concusión, entre otros ${ }^{(39)}$.Y en todos

(35) En este punto, Aboso $(2012,341)$ opina que no queda claro la suerte de la organización cuando el delito no se ejecuta.

(36) En el mismo sentido, véase Schünemann (2004, 34); Bolea Bardón (2000, 346, 349, 387). El dominio del que se habla es uno sobre el aparato, véase Feijoo Sánchez (2007, 166-167).

(37) Es más, suma al sustento de reprochabilidad, la actuación de quien domina un aparato de poder desde un marco de legitimidad formal (como la administración pública), el hecho que se aproveche la fuente legítima del poder, y con ello, se dificulte el trabajo de las autoridades encargadas del control y prevención del delito, Sala Penal Nacional, Expediente: A.V. 19-2001, cit., pp. 637, 639.

(38) La figura jurídica del dominio de la organización puede aplicarse sobre actividades terroristas y determinadas formas de aparición de la criminalidad organizada, en tanto se den sus condiciones en cada caso particular, véase Roxin (2006, 247).

(39) Así da cuenta el Decreto Supremo 017-2008-JUS, "Reglamento del Sistema de Defensa Jurídica del Estado", de fecha 4.12.2008, artículo 46, que entiende que la competencia de la Procuraduría Anticorrupción alcanza a los demás delitos citados. 
Aproximación teórica sobre la aplicación de la autoría mediata por dominio de aparato organizado de poder en supuestos de gran o alta corrupción

A Theoretical Approach to the Application of Command Responsibility for Domain over Organized Power Structures to High Corruption Cases

estos preceptos subyace el principal fundamento del injusto de corrupción: aprovechamiento del poder público en beneficio privado $^{(40)}$, es decir, todos los preceptos citados tendrán que leerse a partir de dichos componentes.

Y desde el sesgo que interesa a las ideas de este trabajo, el legislador peruano no desatiende la complejidad con que funciona la administración pública. Consciente de que no se trata de jirones de poder que cuelgan condenados a jamás rozarse, sanciona al funcionario o funcionaria pública que actúa de forma directa o por persona interpuesta (participación de forma indirecta en razón del cargo), dejando notar que el clásico supuesto de autoría individual y directa no se da abasto, respecto de las formas de criminalidad en espacios de interacción que tienen a la pluralidad de intervinientes como un rasgo distintivo ${ }^{(41)}$.Y esta constatación bien puede ser el preludio de la aplicación de la tesis de autoría mediata por dominio de organización, en casos de gran corrupción.

Dice Meini: “(...) Como organización, el Estado cuenta con una estructura jerárquica manifiestamente fuerte, con cadenas de mando notablemente formalizadas, con divisiones y compartimentajes estandarizados (...) que hacen de él la organización prototípica para aplicar autoría mediata por dominio de organización (...) ¡Qué mejor aparato de poder que el propio Estado!" $(2008,177-179)^{(42)}$.Pero además, como si la idoneidad distributiva y jerarquizada de los cauces burocráticos no fuera suficiente, la compleja composición normativa de la Administración (Feijoo 2007, 124) puede ser determinante para la impunidad procurada por los sujetos con mayor poder político (Meini 2008, 57, 180). Entonces, el supuesto de hecho parece claro: la distribución orgánica de la administración pública puede ser calcada y utilizada como un aparato organizado de poder, en cuya virtud se pueda afirmar la existencia de un supuesto de hecho de gran corrupción.

En este sentido, la mayor cantidad de atribuciones normativas será el primer indicio para conocer quién es el sujeto de atrás (además de los recaudaos que vinculen al superior jerárquico con el hecho delictivo, lógicamente), como también para explicar la importancia material de su aporte. Algo que se condice con la lógica del poder, pues en una estructura vertical como la Administración, cuanto más alto sea el punto de ubicación, serán más los estamentos subordinados y controlados. Sin embargo, aunque la distribución vertical de los estratos indique jerarquía y poder, también es verdad que, en la administración pública cada escaño está dotado de una serie de atribuciones normativas que a la postre servirán para transmitir la orden hasta ejecutarla. Este circuito no solo dispensa razones suficientes para identificar la automaticidad del aparato, sino que sustenta la autoría independiente de los subordinados y subordinadas, en el orden descendente del aparato.

Tal como se mencionó en líneas precedentes y como lo explicitara la Sentencia del Tribunal Supremo Alemán del 26 de julio de 1993, para el caso de los disparos en el Muro de Berlín (Marín de Espinosa Ceballos $2002,58)$, el hombre de atrás tiene el dominio del hecho cuando aprovecha determinadas condiciones marco pre-configuradas por unas estructuras de organización, a sabiendas de la automaticidad que se desencadenará cuando emita la orden delictiva(43). No obstante, la cúspide del aparato puede contribuir a la automaticidad del mismo, cuando, por ejemplo, uno de los elementos de cohesión de la organización sea la filiación política, ordenando la contratación de sus más fieles correligionarios, en puestos claves de una entidad pública, garantizando así, la realización ordenada y previsible del delito, reafirmando el cuarto elemento de la tesis. Dicho de otro modo, y aunque la idea original de la teoría sugiera lo contrario, los extremos del aparato pueden tener algún tipo de contacto, y, en el supuesto mencionado, ello redundaría en su automaticidad. Con este aditivo, el superior jerárquico, que comete el delito indirectamente ${ }^{(44)}$, no solamente controlaría el aparato desde el plano normativo, sino además, desde una realidad fáctica, en virtud de espurias relaciones (ajenas a las que deben primar en la Administración) que le vinculan con sus subordinados (y que tienen tinte político).

De otro lado, sin que sea una cuestión explícita en los fundamentos primigenios de la tesis, no es necesario que la orden emanada del vértice más alto de la organización mantenga el mismo nomen iuris hasta su ejecución. El hombre de atrás no ordena la comisión de un tipo penal específico del

(40) Por todos, Terradillos Basoco (2016a, 147); Pritzl (2000, 17).

(41) La forma cómo funciona la Administración se refleja sin más en la comisión de delitos de corrupción: mecanismos complejos, coordinados y estratégicos, véase De la Mata Barranco (2004, 4); Acale Sánchez (2007, 28; 2017, 6).

(42) En el mismo sentido, véase Ambos (2011, 12); Zaffaroni (2012, 12-13).

(43) El dominio del que se habla es uno sobre el aparato, véase Feijoo Sánchez $(2007,171)$

(44) Sala Penal Nacional, Expediente Acumulado No. 560-2003, cit., página 165. 
CP (con la descripción gráfica de sus elementos objetivos, subjetivos, agravantes, etc.), sino que delinea los contornos generales de un hecho ${ }^{(45)}$, el mismo que podría representarse en más de un tipo penal. Por ejemplo, si la Presidenciae de la Nación ordena un contrato de infraestructura pública con una específica empresa brasilera, el derrotero de dicha orden podrá requerir de más de un cohecho, de algunos tráficos de influencias, otras negociaciones incompatibles y, por supuesto, producirá el enriquecimiento ilícito de los miembros del aparato. Ergo, la automaticidad de la organización disgrega la orden en tantos comportamientos típicos, como gestiones sean necesarias para cumplirla.

Desde este punto de vista, la falta de meticulosidad en la tipicidad de la orden emitida es una condición que reafirma la autonomía del sujeto de delante, cuya discrecionalidad lo vuelve autor del delito. Él domina el hecho de la parte del plan criminal que sus competencias normativas le permiten ejecutar, en las entrañas del cuerpo burocrático del Estado.

Por lo demás, la negativa del ejecutor material de un aparato de poder usado para cometer delitos de corrupción pública es poco probable, pues todos y cada uno de los miembros de la organización tienen más de una razón para obedecer las órdenes: agradecimiento por el puesto de trabajo concedido de forma discrecional a manos del hombre de atrás, lealtad al partido político (protección al líder político), beneficio personal obtenido por la operación corrupta, riesgo de autoincriminación ${ }^{(46)}$, etc.

Del mismo modo que no era normal que ante la orden de matar a los fugitivos que intenten cruzar el Muro de Berlín, algunos soldados hayan perdonado la vida de los que lo intentaran (Roxin 2006, 246), en el caso concreto, y en general en los casos de corrupción política(47), es muy difícil suponer alguna disidencia, denuncia o rechazo de la orden, principalmente por las razones ya dichas (pero, además, una hipótesis por constatar será que la fungibilidad de los miembros del aparato de poder, en ciertos casos, podría ser expendida por el partidismo político). Con todo, por regla general, y contando con la predisposición de los integrantes, los estratos más bajos de la Administración cuentan con mayor personal que los puestos intermedios y altos, con lo cual, incluso manteniendo la autonomía del criterio de fungibilidad, la administración pública calza como horma exacta de aplicación de la tesis de autoría mediata por dominio de aparato de poder.

Tal como se comentó supra, la especial disposición a cometer el delito es un requisito indispensable y fundante de la tesis objeto de análisis. Y ello puede resumirse en una máxima de la experiencia aplicada a cualquier grupo criminal "(...) Para formar parte del grupo, el imputado debe precisamente compartir la finalidad delictiva común, el propósito delictivo, o la intención de cometer el delito (...)" (Kiss 2013, 27). Por ende, sin que importe tanto la cantidad de elementos fungibles, como la adscripción al plan criminal de todos los involucrados, el automatismo de la organización se sostiene en la disposición a cometer el hecho de sus integrantes (algo que también puede ser explicado, para algunos casos, centrando el análisis en el partidismo político). Y la prueba fáctica de esta afirmación se encuentra en el hecho de que el empresario interesado en el contrato público (para seguir con el ejemplo), precisamente porque es consciente que fue el miembro más poderoso del aparato quien ha emitido la orden, no pierde tiempo en la tarea de refrendar-con el superior jerárquico- el acto del subordinado, y seguirá adelante durante el proceso administrativo de adjudicación de la obra pública, que finalmente logrará de manera ilegal.

Finalmente, la contratación fraudulenta de la obra pública, decisión que en el ejemplo proviene de las atribuciones políticas del Poder Ejecutivo, esto es, de un poder

(45) Las órdenes formales son propias de los mandos superiores en un aparato de poder, pero ello no enerva la posibilidad de que también dispongan cuestiones materiales para la comisión del delito, véase Sala Penal Nacional, Expediente: A.V. 19-2001, cit., p. 638.

(46) En los delitos de alta corrupción, la denuncia del subordinado desbarataría por completo la organización, pues la relevancia política y mediática de este tipo de criminalidad (sin que se asegure sanción contra los responsables) paralizaría la comisión de hechos delictivos. Sin embargo, su valía para frustrar el aparato de poder no ubica al ejecutor material en alguna escala más alta de la organización. El absoluto poder de mando se decide desde el funcionamiento de la organización, no en las posibilidades de su destrucción; si no fuese así, el meticuloso periodista o el policía acucioso que descubre la trama serían, también, los sujetos de atrás. Por lo demás, cuanto menos en la experiencia peruana, el descubrimiento de la trama corrupta se desvela desde sus participantes, mandos medios que deciden acogerse a procesos premiales de colaboración o delación.

(47) Desde el plano sociológico, la corrupción es esencialmente política, véase Terradillos Basoco (2017, 2). Sin embargo, el crimen de corrupción puede ser abordado desde distintos puntos de vista, que dependerán del observador que se trate, véase De la Mata Barranco $(2016,4)$.

(48) Como lo dice la sentencia de la Cámara Federal de Apelaciones en lo Criminal y Correccional Federal de la Capital Federal de la República de Argentina, véase Aboso, (2012, 319). 
ajeno al control del simple ejecutor material, no puede ser consecuencia del actuar errático e individual de los operadores subordinados $^{(48)}$. Y esto es así, porque una orden ilegal al interior de la Administración solo puede pervivir cuando quien la emite no solamente se ubica en el vértice más importante de la misma, sino que la controla, gracias al poder normativo que ostenta (Bolea Bardón 2000, 370)(49), dejando al ejecutor material no más que las circunstancias de trámite y ejecución de su orden (Aboso 2012, 304; Roxin 2006, 243). Y con la atención puesta en esta última constatación, la posibilidad de vincular al superior jerárquico en delitos de alta corrupción, a través de la teoría del autor mediato por dominio de organización, es bastante razonable.

\section{Conclusiones}

El concepto de gran corrupción permite escindir una concreta tipología criminal, que se caracteriza por la sinergia del poder político y del poder económico, pero además, por la existencia de una estructura organizativa que pone en funcionamiento dichos engranajes de poder. Los elementos de esta tipología criminológica explican, también, el grave impacto sobre las bases constitutivas del Estado y la sociedad: ineficiencia del gasto público, desigualdad social, deslegitimación de las instituciones democráticas, etc.

La estructura organizativa tiene una valía bifronte: por un lado, explica la confluencia del poder político y del poder económico, y de otro lado, hace referencia al calco delictivo del organigrama burocrático. Este último punto significa la utilización, para la comisión del delito de corrupción, de un complejo sistema de distribución de competencias y posiciones jerarquizadas de poder y subordinación, que, además, suman a efectos de generar impunidad de los principales responsables.

En esta tesitura, la aplicación de la tesis de la autoría mediata por dominio de organización o aparato de poder parece razonable, pues los causes burocráticos pueden ordenar verticalmente la comisión del delito de corrupción, asegurando así la relación de idoneidad material entre el automatismo del aparato y la comisión del hecho delictivo. Es más, las especiales características de composición política de la Administración redundan en la pertinencia de los elementos de la autoría mediata como criterio de imputación contra los superiores jerárquicos del organigrama público.

Finalmente, la evolución criminal no puede (o no debe) trascurrir libremente sin que las herramientas de imputación del Derecho Penal sigan sus pasos. Y en aras de dicha nivelación, imputar responsabilidad penal contra los altos mandos que se sitúan alejados normativa y fácticamente del hecho delictivo en concreto, pero que al mismo tiempo guarecen sus linderos de definición y determinación, no solamente es una cuestión de análisis doctrinal o dogmático, sino, un asunto de justicia.

\section{Referencias bibliográficas}

Acale Sánchez, María. 2017. Limitaciones Criminológicas y Normativas del Concepto de Corrupción. En La Proyección de la Corrupción en el Ámbito Penal: Análisis de una Realidad Transversal, dir. Puente Alba, Luz María, 3-40. Granada: Comares.

2007. Tratamiento de la corrupción urbanística en el Proyecto de Ley Orgánica de reforma del Código Penal del 15 de enero de 2007. La Ley Penal. Revista de Derecho Penal, Procesal y Penitenciario 38: 5-30.

Aedo, Cristian. 1996. Reflexiones sobre la corrupción. En Eficiencia, corrupción y crecimiento con equidad, AA.VV., 2128. Bilbao: Aula de ética. Universidad de Deusto.

Amisano Tesi, Maristella. 2011. Le tipologie della corruzione. Torino: G. Giappichelli Editore.

Aboso, Gustavo Eduardo. 2012. Los Límites de la Autoría Mediata. Criterios para la justificación del sujeto instrumento por parte del autor mediato. Buenos Aires: BdeF.

Ambos, Kai. 2015. El Caso Eichmann. Traducción de Leandro Díaz. Anuario de Derecho Penal y Ciencias Penales 68, 1(enero): 79-98.

2011. Sobre la "organización" en el dominio de la organización. Traducción de Fernando Tarapués y Ricardo Robles Planas.

(49) La intervención del hombre de atrás y el sustento de su poder al interior de la organización podría resumirse en la siguiente afirmación: "(...) los criterios materiales de definición del dominio han de venir impuestos normativamente, partiendo de las prescripciones legales, los principios axiológicos que informan el ordenamiento jurídico y la propia realidad fáctica (...)”, véase Bolea Bardón (2000, 401); Roxin (2000a, 274-276); Aboso (2012, 320). 
InDret. Revista para el Análisis del Derecho 3(julio): 1-25. http:// www.indret.com/pdf/839.pdf.

Asua Batarrita, Adela. 1997. La tutela penal del correcto funcionamiento de la Administración. Cuestiones político criminales, criterios de interpretación y delimitación respecto a la potestad disciplinaria. En Delitos contra la Administración Pública, edit. Asua Batarrita, Adela. Bilbao: Instituto Vasco de Administración Pública.

Berdugo, Ignacio. 2012. Viejo y Nuevo Derecho Penal. Madrid: lustel.

Bolea Bardón, Carolina. 2000. Autoría Mediata en Derecho Penal. Valencia: Tirant lo Blanch.

Burneo Labrín, José. 2009. Corrupción y Derecho Internacional de los derechos humanos. Derecho PUCP 63(noviembre): 333-347.

Cervini, Raúl y Adriasola, Gabriel. 2005. El Derecho Penal de la Empresa desde una visión garantista. Buenos Aires Montevideo: BdeF.

Cigüela Sola, Javier. 2016. El injusto estructural de la organización. Aproximación al fundamento de la sanción de la persona jurídica. InDret. Revista para el Análisis del Derecho 1(enero): 1-28. http://www.indret.com/pdf/1200. pdf.

Cingari, Francesco. 2011. Possibilità e limiti del diritto penale nel contrasto alla corruzione. En Corruzione pubblica. Repressione penale e prevenzione ammnistrativa, edit. Francesco Palazzo, 9-50. Firenze: Firenze University Press.

Cordini, Nicolás. 2017. El "crimen organizado" y el problema de la doble vía de punición. Revista de Derecho (Valdivia) 30, 1(junio): 333-349. https://doi.org/10.4067/s0718-09502017000100014

Correcher Mira, Jorge. 2015. Análisis jurisprudencial de los delitos contra la Administración pública en el territorio valenciano. En Corrupción Pública. Cuestiones de Política Criminal (II): La Comunitat Valenciana, dir. Jareño Leal, Ángeles, 21-79. Madrid: lustel.

De Cassia Biason, Rita. 2017. La operación Lava Jato y el control de la corrupción en Brasil. Traducción de Olga Álvarez. En Poder Ciudadano: corrupción y transparencia. Informe 2016/2017, Katz, Alejandra y otros, 61-83. Buenos Aires: Eudeba.

De la Cuesta Arzamendi, José Luis. 2003. Iniciativas internacionales contra la corrupción. Eguzkilore 17(diciembre): 5-26. https://www.ehu.eus/documents/1736829/2174325/ Eguzkilore+17.4+CUESTA.pdf.

De la Mata Barranco, Norberto. 2016. La lucha contra la corrupción política. Revista Electrónica de Ciencia Penal y Criminología 18: 1-25. http://criminet.ugr.es/recpc/18/ recpc18-01.pdf.
Norberto. 2004. La respuesta la corrupción pública. Tratamiento penal de la conducta de los particulares que contribuyen con ella. Granada: Comares.

Di Gennaro, Giuseppe. 1993. La Criminalità Organizzata Nell'Esperienza Internazionale. En La Criminalità Organizzata Negli Anni'90 Strumenti di Lotta E Nuove Strategie, edit. De Cataldo, L e Tinebra, G., 5-19. Padova: CEDAM

Díaz y García Conlledo, Miguel. 1991. La Autoría en Derecho Penal. Barcelona: PPU.

Escalante-Barreto, Caviedes. 2017. Crimen organizado y problemas dogmáticos de autoría y participación: análisis comparado de Colombia y España en el marco de la lucha contra el delito en la Organización de las Naciones Unidas. Pensamiento Jurídico 45 (julio): 97-125. https://revistas.unal.edu.co/ index.php/peju/article/view/65669/pdf.

Faraldo Cabana, Patricia. 2008. Posibilidades de Aplicación de la Autoría Mediata con Aparatos Organizados de Poder en la Empresa. En Cuestiones Actuales de Derecho Penal Económico, dir. Serrano-Piedecasas, José Ramón y Demetrio Crespo, Eduardo, 89-129. Madrid: Colex.

Patricia. 2004. Responsabilidad Penal del Dirigente en Estructuras Jerárquicas. Valencia: Tirant lo Blanch.

Feijoo Sánchez, Bernardo. 2007. Derecho Penal de la Empresa e Imputación Objetiva. Madrid: Reus.

Fernández Teruelo, Javier. 2015. El fenómeno de la corrupción en España: respuesta penal y propuesta de reforma. En Economía y Derecho penal en Europa: una comparación entre las experiencias italiana y española, edit. Puente Alva, Luz María, 55-76. A Coruña: Universidade da Coruña.

Ferrajoli, Luigi. 1996. El Estado Constitucional de Derecho Hoy: EL Modelo y su Divergencia de la Realidad. En Corrupción y Estado de Derecho. El papel de la jurisdicción, edit. Ibáñez, Perfecto, AA.VV., 15-29. Madrid: Tecnos.

García Cavero, Percy. 2009. La autoría mediata por dominio de la voluntad en aparatos de poder organizados: El caso 
Aproximación teórica sobre la aplicación de la autoría mediata por dominio de aparato organizado de poder en supuestos de gran o alta corrupción

A Theoretical Approach to the Application of Command Responsibility for Domain over Organized Power Structures to High Corruption Cases

de Alberto Fujimori Fujimori. Zeitschrift für Internationale Strafrechtsdogmatik 11: 596-602. https://www.unifr.ch/ddp1/ derechopenal/articulos/a_20091207_05.pdf.

González Más, José Luis. 2012. Instrumentos Jurídicos contra el Crimen Organizado. En Criminalidad y Globalización. Análisis y estrategias ente grupos y organizaciones al margen de la Ley, coord. Magaz Álvarez, Ricardo, 143-196. Madrid: Instituto Universitario General Gutiérrez Mellado-UNED.

Grisolía G., Francisco. 2004. El Delito de Asociación llícita. Revista Chilena de Derecho 1: 75-88.

Górriz Royo, Elena. 2008. El Concepto de Autor en Derecho Penal. Valencia: Tirant lo Blanch.

Hava García, Ester. 2016. Gran corrupción: estrategias para evitar su impunidad internacional. Revista Nuevo Foro Penal 12, 87(diciembre): 60-98. https://doi.org/10.17230/nfp.12.87.2

Hernández Plasencia, José Ulises. 1996. La autoría mediata en Derecho penal. Granada: Comares.

Iglesias Río, Miguel Ángel. 2001. Criminalidad organizada y delincuencia económica: aproximación a su incidencia global. En El nuevo derecho penal español. Estudios penales en memoria del profesor José Manuel Valle Muñiz, coord. Quintero, Gonzalo, tom. II, 1445-1472. Madrid: Editorial Aranzadi.

Jakobs, Günther. 1997. Derecho Penal Parte General. Fundamentos y Teoría de la Imputación. Traducción de Joaquín Cuello Contreras y José Luis Serrano Gonzáles de Murillo, $2^{\text {a }}$ ed. Madrid: Marcial Pons.

Kaufmann, Daniel. 2000. Corrupción y Reforma Institucional: el poder de la evidencia empírica. Revista Perspectivas 2(mayo): 367-387. http://www.dii.uchile.cl/ revista/ArticulosVol3-N2/06Kaufmann_s_parr.pdf.

Kiss, Alejandro. 2013. La contribución en la comisión de un crimen por un grupo de personas en la jurisprudencia de la Corte Penal Internacional. InDret. Revista para el Análisis del Derecho 2(abril): 1-34. http://www.indret.com/pdf/964.pdf.

Klitgaard, Robert. 1988. Controlling Corruption. Los Angeles: University of California Press, Berkeley.

Kupatadze, Alexander. 2015. Political corruption in Eurasia: Understanding collusion between states, organized crime and business. Theoretical Criminology 2(abril): 198-215. https://doi. org/10.1177/1362480615574404.

Marín De Espinosa Ceballos, María B. 2002. Criminalidad de Empresa. La responsabilidad penal en las estructuras jerárquicamente organizadas. Valencia: Tirant lo Blanch.

Marine, Frank. 2006. The effects of organized crime on legitimate businesses. Journal of Financial Crime 13, 2(abril): 214-234. https://doi.org/10.1108/13590790610660926
Matellanes Rodríguez, Nuria. 2012. El delito de cohecho de funcionarios nacionales en el código penal español: condicionantes internacionales y principales aspectos de su nueva regulación. En Estudios sobre la Corrupción una reflexión Hispano Brasilera, coords. Berdugo Gómez de la Torre, Ignacio y Liberatore S. Bechara, Ana, 275-302. Salamanca: Centro de Estudios Brasileros Universidad de Salamanca.

Mauro, Paolo. 1995. Corruption and Growth. The Quarterly Journal of Economics 110, 3(agosto): 681-712. https://doi. org/10.2307/2946696.

Mcintosh, Mary. 1977. La organización del crimen. Traducción de Nicolás Grab. México DF.

Meini, Iván. 2008a. El domino de la organización en Derecho penal. Lima: Palestra.

.2008b. Delitos contra la Administración Pública. Ciudad de Guatemala: USAID.

2007. La autoría mediata de Abimael Guzmán. Memoria, Revista Sobre Cultura, Democracia y Derechos Humanos 1: 49-57.

Méndez Rodríguez, Cristina. 2014. Los delitos de pertenencia a organización criminal y a grupo criminal y el delito de tráfico de drogas cometido por persona que pertenece a una organización delictiva. Crónica de un conflicto normativo anunciado y análisis jurisprudencial. Estudios Penales y Criminológicos XXXIV: 511-560.

Morra, Mario. 2004. Corruzione e concussione. Nuovi problemi e questioni controverse. Torino: G.Giappichelli Editore.

Lopes Junior, Elias, Façanha Câmara, Samuel, Gomes Rocha, Leonino y Brasil, Alexander. 2018. Influence of corruption on state-owned enterprise expenditures. Brazilian Journal of Public Administration 4(agosto): 695-711. http://dx.doi.org/10.1590/0034-7612173631.

Olásolo Alonso, Héctor. 2013. Tratado de Autoría y Participación en Derecho Penal Internacional. Valencia: Tirant lo Blanch.

Peñaranda Ramos, Enrique. 2008. Autoría y Participación en la Empresa. En Cuestiones Actuales de Derecho Penal Económico, dir. Serrano-Piedecasas, José Ramón y Demetrio Crespo, Eduardo, 161-186. Madrid: Colex. 
Pérez Cepeda, Ana Isabel. 2004. Globalización, tráfico internacional ilícito de personas y derecho penal. Granada: Comares.

Pritzl, Rupert F.J. 2000. Corrupción y rentismo en América Latina. Buenos Aires: Fundación Konrad.

Raffo López, Leonardo y Gómez Calderón, Diego. 2017. Redes criminales y corrupción en la era del microtráfico y el narcomenudeo. Revista de Economía Institucional 19, 37 (diciembre): 227-261. https://doi.org/10.18601/01245996. v19n37.12.

Rose-Ackermann, Susan. 2001. Desarrollo y Corrupción. Traducción de Cristina Alba Muñoz. Gestión y Análisis de Políticas Públicas 21 (mayo-agosto): 5-21. https://doi. org/10.24965/gapp.vi21.260.

Roxin, Claus. 2009. Dirección de la organización como autoría mediata. Traducción de Manuel Abanto Vásquez. Anuario de Derecho Penal y Ciencias Penales LXII: 51-65.

2006. El dominio de organización como forma independiente de autoría mediata. Traducción de Justa Gómez. Revista Penal 18 (julio): 242-248. http://rabida.uhu.es/dspace/ bitstream/handle/10272/12247/Dominio.pdf?sequence=2.

2000a. Autoría y Dominio del Hecho en Derecho Penal. Séptima edición alemana. Traducción de Joaquín Cuello Contreras y José Luis Serrano González de Murillo. Madrid: Marcial Pons.

2000b. Formas de intervención en el delito. Estado de la Cuestión. En Sobre el Estado de la Teoría del Delito: Seminario en la Universidad Pompeu Fabra, 155-178. Traducción de Jesús María Silva Sánchez, María Teresa Castiñeira Palou, Pablo Sánchez-Ostiz Gutiérrez, David Felip I Saborit, Ramón Ragués I Vallés, Ricardo Robles Planas y Javier Sánchez-Vera Gómez Trelles. Madrid: Civitas.

Rusconi, Maximiliano, López, Hernán y Kierszenbaum, Mariano. 2011. Autoría, infracción de deber y delitos de lesa humanidad. Buenos Aires: Ad Hoc.

Sabán Godoy, Alfonso. 1991. El marco jurídico de la corrupción. Madrid: Civitas.

Sánchez García de Paz, Isabel. 2008. Problemas de legitimidad de una respuesta excepcional frente a las organizaciones criminales. En Política Criminal en Vanguardia. Inmigración clandestina, terrorismo, criminalidad organizada, coords. Cancio Meliá, Manuel y Pozuelo Pérez, Laura, 451-494. Navarra: Civitas Thomson.

Sánchez-Vera Gómez-Trelles, Javier. 1998. Sobre la figura de la autoría mediata y su tan sólo fenomenológica "trascendencia". Anuario de Derechos Penal y Ciencias Penales LI: 319-363.

Schünemann, Bernd. 2004. El Tempestuoso desarrollo de la figura de la autoría mediata. Traducción de María Carolina
Palma Vargas. Derecho Penal y Criminología 25: 27-46. http://revistas.uexternado.edu.co/ index.php/derpen/article/view/1038/982.

Terradillos Basoco, Juan María. 2017. Corrupción Política: Consideraciones Político Criminales. Revista Electrónica de Estudios Penales y de la Seguridad 1: 1-37. https://www.ejcreeps.com/Juan $\% 20$ Terradillos $\% 20$ corrupcion $\% 20$ politica $\% 20$ REEPS.pdf.

2016a. Mercado y Administración Pública / Criminalidad Económica y corrupción política. En El Derecho Penal en tiempos de cambio. Libro Homenaje al profesor Luis Fernando Niño, coord. Medina Cuenca, Arnel, 144-176. La Habana: UNIJURIS.

2016b. Terrorismo yihadista y política criminal del siglo XXI. Revista Nuevo Foro Penal 12, 87(diciembre): 18-59. https://doi. org/10.17230/nfp.12.87.1.

Buenos Aires.

2001. Empresa y Derecho penal.

Villegas Díaz, Myrna. 2018. Corrupción y Criminalidad organizada. Aproximaciones al terrorismo, contraterrorismo y tráfico de armas. Revista de Estudios de la Justicia 28(julio): 5176. doi:10.5354/0718-4735.2018.50371.

Virgolini, Julio. 2004. Crímenes excelentes. Delitos de cuello blanco, crimen organizado y corrupción. En Colección Tesis Doctoral 2, dir. Hendler, Edmundo y Tedesco, Ignacio. Buenos Aires: Editores del pueblo.

Wyatt, Tanya; Johnson, Kelly; Hunter, Laura; George, Ryan y Gunter, Rachel. 2018. Corruption and Wildlife Trafficking: Three Case Studies Involving Asia. Asian Criminology 13(marzo): 35-55. https://doi. org/10.1007/s11417-017-9255-8.

Zaffaroni, Raúl. 2012. "Introducción" a Criminología, Civilización y Nuevo Orden Mundial de Wayne Morrison. Revista Crítica Penal y Poder 2(marzo): 1-17. http://revistes. ub.edu/index.php/CriticaPenalPoder/article/ viewFile/2942/3178.

Zúñiga Rodríguez, Laura. 2016. El concepto de criminalidad organizada transnacional: problemas y propuestas. Revista Nuevo Foro Penal 12, 86(junio): 62-114. https://doi. org/10.17230/nfp.12.86.2. 
Aproximación teórica sobre la aplicación de la autoría mediata por dominio de aparato organizado de poder en supuestos de gran o alta corrupción

A Theoretical Approach to the Application of Command Responsibility for Domain over Organized Power Structures to High Corruption Cases

2012. Culpables, Millonarios e Impunes: el difícil tratamiento del Derecho penal del delito de cuello blanco. En Poder y Delito: Escándalos Financieros y Políticos, coords. Zúñiga, Laura; Gorjón, Concepción; Fernández, Julio y Díaz, Lina, 27-47. Salamanca: Ratio.
2002. Redes Internacionales y Criminalidad: A Propósito del Modelo de "Participación en Organización Criminal". En El derecho penal ante la globalización, coords. Zúñiga, Laura; Méndez, Cristina y Díaz, Diego, 51-71. Madrid: Colex.
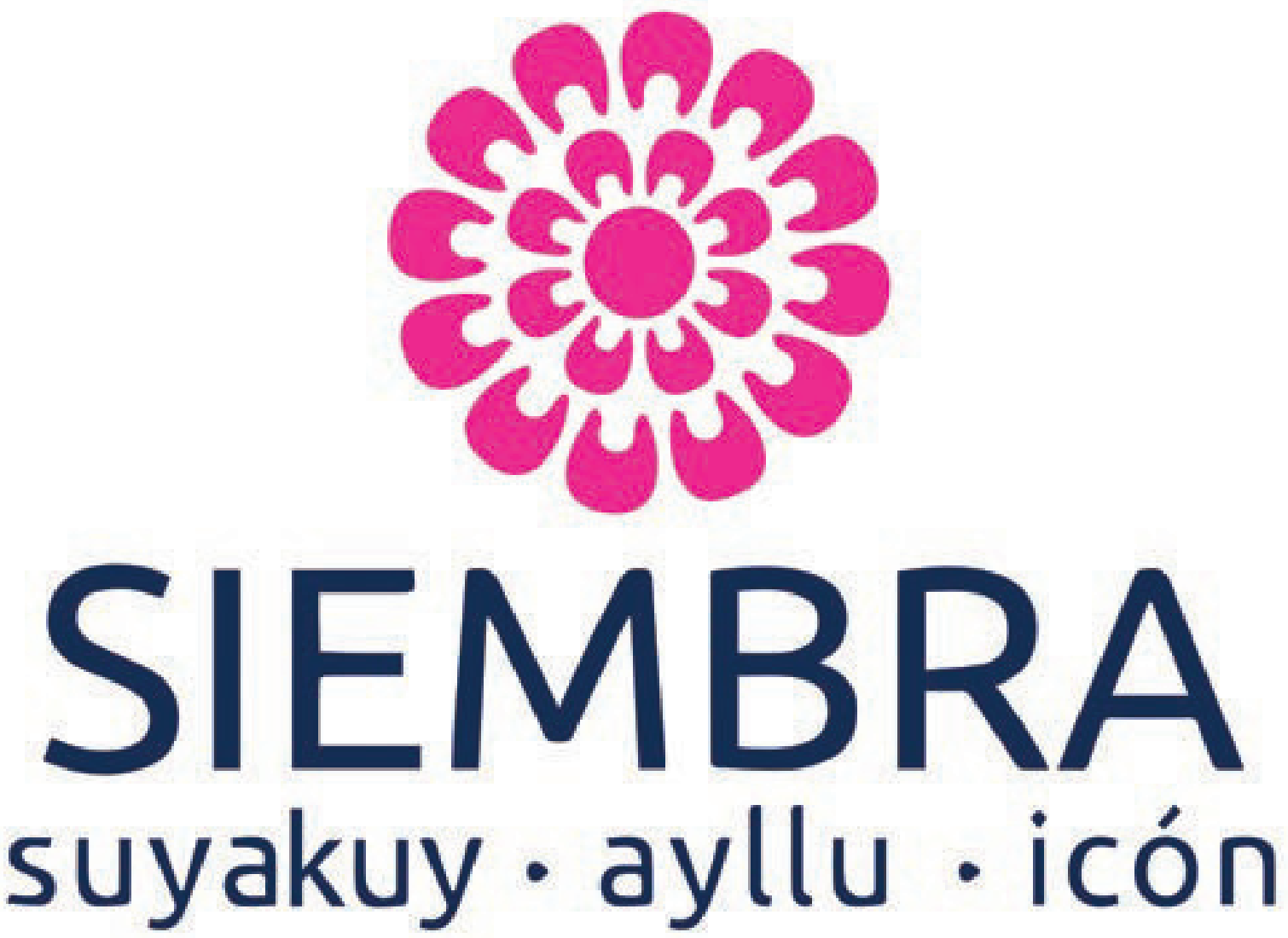